to Perutz's subsequent success with protein structure. On a bizarre level, he was interested in crystal dislocations and, much to the amazement of his colleagues and first-year undergraduates, was able to simulate their motion with rafts of bubbles.

On retirement from the Cavendish, Lawrence became resident professor at the Royal Institution. There he built up a powerful group, led by David Phillips, that solved the first structure of an enzyme. In his lifetime, Lawrence saw X-ray crystallography grow from the seed he helped germinate to a method of solving the structures of the largest macromolecules.

The subtitle of Graeme Hunter's book refers to Lawrence's "life and science". The 'life' section is full of anecdotes and makes fascinating reading. Hunter captures the lonely schoolboy and tells of Alice Bragg - who some of us remember as a rather formidable justice of the peace - as a lively young flapper. He brings out Lawrence as an artist. Moreover, although Lawrence tried to avoid confrontation, his appointment to succeed Edward Andrade at the Royal Institution was accompanied by bad feelings and tension, which is fairly portrayed and analysed by Hunter.

The science is more of a problem. Most of it seems fairly accurate, but one or two sections reminded me of the description of the farm in Stella Gibbons' Cold Comfort Farm, in which the detailed geometrical descriptions resist synthesis. Hunter, who is not a crystallographer, must be commended for his brave attempt to put the science where it really belongs. However, his lack of a real understanding of diffraction theory shows up in numerous mini-howlers.

For example: " $n \lambda=2 d \sin \theta \ldots$ this was the famous Bragg equation. However, there was nothing really novel about it ... for a line grating, $2 e \sin \theta=n \lambda$. . Apart from the $\theta$ being different, Hunter misses the point first made by von Laue that diffraction from a threedimensional lattice is subject to constraints not pertinent for a one-dimensional grating. The Bragg law imposes two conditions: specular reflection and the Bragg equation.

Hunter's lack of comprehension leads to an even bigger howler in Figure 0.2 in the introduction, which is supposed to help the lay reader. Hunter's putative Bragg reflections do not satisfy the Bragg equation, and moreover show that high-order reflections come out at low diffraction angles, and loworder reflections come out at high angles of diffraction; this is exactly the wrong way round. The strange thing is that a bit later, in Figure 2.7, he gets it right. The book, which could easily have been rescued by rigorous professional editing, is already in need of a second edition.

Kenneth C. Holmes is in the Department of Biophysics, Max-Planck-Institut für Medizinische Forschung, Heidelberg 69120, Germany.

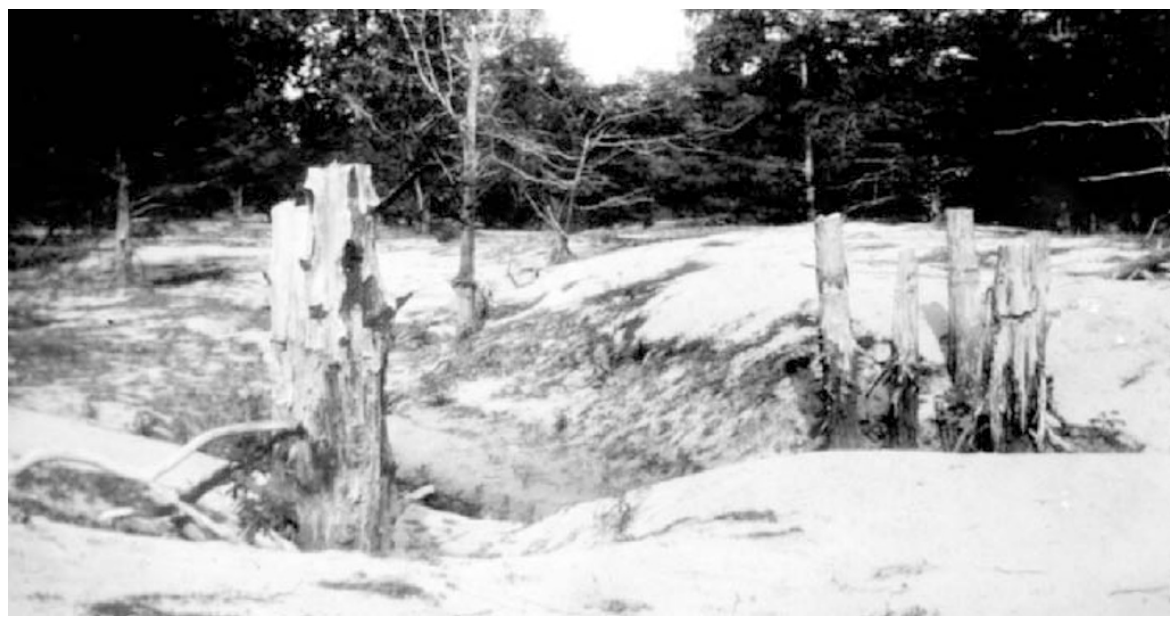

Driving force: the New Madrid earthquakes moved the earth, but did they reshape geology?

\section{Shaking up seismology}

The Big One: The Earthquake That Rocked Early America and Helped Create a Science

by Jake Page \& Charles Officer

Houghton Mifflin: 2004. 220 pp. \$24

\section{Naomi Oreskes}

In the winter of 1811-12, three major earthquakes struck an area of the North American mid-continent in rapid succession. According to eye-witnesses, the ground ruptured profoundly in numerous locations, lakes appeared where there had been none, and the mighty Mississippi River flowed backwards. The earthquakes, felt as far away as Montreal in Canada, affected an area of more than a million square miles. Their magnitudes have since been estimated at between 7.8 and 8.3, greater than the 7.6 of the famous San Francisco earthquake of 1906, making them among the most powerful quakes to strike the United States in recorded history.

The United States was then a young and sparsely settled country, and the theory of plate tectonics was far in the future, so there is no meaningful sense in which these earthquakes could have been considered "anomalous" at the time. Nonetheless, they are scientific anomalies now: the theory of plate tectonics explains large earthquakes as the release of stress built up as the Earth's crustal plates slowly grind past one another, but the quakes of New Madrid (to rhyme with Hagrid) occurred nowhere near a plate boundary.

If the theory of plate tectonics does not explain 'intra-plate' earthquakes, then what caused the New Madrid quakes? And why hasn't this conspicuous anomaly caused a crisis for the current theory? These are intriguing questions, and The Big One begins with the promise of answering them. Unfor- tunately, that promise remains unfulfilled.

The book opens with a fast-paced description of the events of that winter and the background to European settlement in the region. It then changes tack: most of the rest of the book is a historical discussion of developments in the Earth sciences, leading to present-day theories of the origins of the New Madrid events. Sadly, this material is filled with factual errors and presents little that is not better treated elsewhere.

It would be tedious to recount the numerous mistakes and misrepresentations; a few will suffice to make the point. Lord Kelvin did not originate the idea that Earth was progressively cooling; that honour, if that's what it is, belongs to Georges-Louis Leclerc de Buffon, Immanuel Kant and Pierre Laplace. Isostasy - the theory that the Earth's crust sits in hydrostatic equilibrium on a denser substrate - is not the theory of glacial rebound; glacial rebound is merely one example of an isostatic effect. Alfred Wegener, the author of continental drift theory, did not die attempting to bring help to stranded members of his 1930-31 Greenland expedition, but on a trip to equip an inland observation station (see http:// www.awi-bremerhaven.de/AWI/geschichte/ germanexpedition-e.html). And no one in the 1920s pejoratively called Wegener's work "geopoetry" - that term was introduced later by the Dutch geophysicist J. H. F. Umbgrove as an approbative term for creative speculation, a concept later used to great effect by US geologist Harry Hess.

The authors' treatment of continental drift and plate tectonics is particularly beset by peculiar biases. They perpetuate the well worn but erroneous view that continental drift was rejected for lack of a causal mechanism, but in fact mantle convection was widely discussed in the 1920s and 1930s as a plausible mechanism. They credit the idea of mantle convection to seismologist Beno Gutenberg at Caltech in the 1950s, but its earliest prominent and credible advocate was the British geologist Arthur Holmes, 


\section{From art to environment}

\section{Betty Beaumont's Ocean Landmark is in deep water.}

\begin{abstract}
Martin Kemp
Artists have long made large-scale interventions in the landscape. My house in Woodstock in Oxfordshire overlooks Blenheim Park, in which a magnificent landscape with a lake, a palladian bridge, rolling hills and clumped trees was sculpted in the 1760 s by Lancelot 'Capability' Brown. Reshaping the land in this way requires patience: the scene progressively matures as the trees grow to full majesty and the ecology of the new topography organizes itself. More recently, 'land art' has involved the construction of huge artworks in specific locations, most notably the great Spiral Jetty constructed in 1970 by Robert Smithson at Rozel Point on the Great Salt Lake, Utah.

Betty Beaumont, an artist born
\end{abstract} in Toronto, Canada, but based in New York, follows this tradition of reshaping landscapes, but with key differences. Her interventions are directed specifically at social awareness, setting up environmental processes over long periods of time, rather than making monuments to be viewed in the time-honoured way. Indeed, the grandest of her long-term projects, Ocean Landmark, now almost 25 years old, cannot be readily viewed, as it lies deep in ocean water.

In 1978, Beaumont started work with a team of scientists to transform processed coal waste from a hydroelectric power plant in Ohio into inert rectangular blocks. Some 500 tons of the coal fly-ash blocks, 17,000 in number and cast at a concrete plant in Pennsylvania, were transported by barge in 1980 to a site on the continental shelf in the Atlantic Ocean, 40 miles from New York Harbor and 3 miles off Fire Island National Seashore. They were deposited on the sea floor to form a large mound.

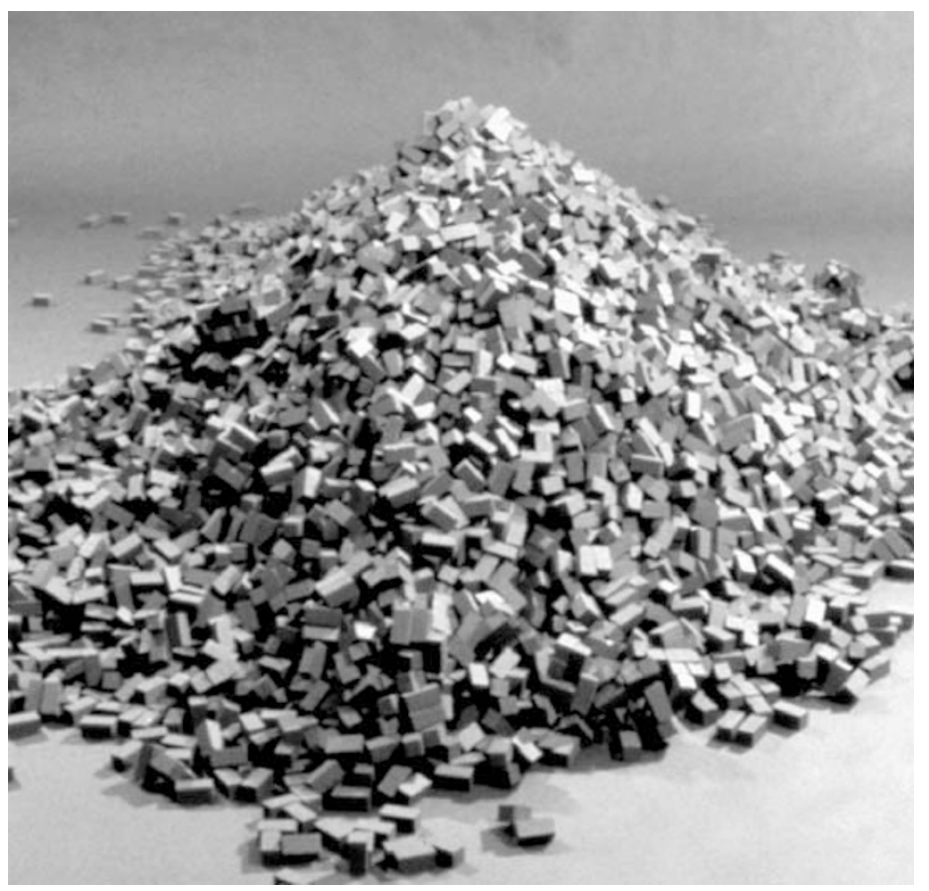

'idea' as a real artwork. Although this artwork cannot be seen, each of us can visualize it."

Beaumont uses various strategies to meet our desire to see her work. One method, shown here, is to create a pile of scaled-down blocks as a surrogate for the underwater reef, but without, of course, the ecological accretions. Other strategies involve the sort of multimedia displays that naturalhistory museums use to portray aspects of nature.

Beaumont explains: "Current technology enables me to image this work in its life-giving, mature condition and in its entire form. Using global positioning satellite technology, the work can be located and images created through the use of underwater remote sensing and side-scan sonar. Coded in the images of the now-evolved underwater sculp-

Over the years, the austere blocks have been transformed into a lush reef, a rich ecosystem teeming with fish. Such has been the success of the project that it is is listed as a 'fish haven' by the National Oceanographic and Atmospheric Administration.

Beaumont is fascinated by two time frames. The first consists of the ancient laying down of coal, the modern generation of power and the simultaneous production of waste. She completed the cycle with her team: "We took this material, transformed it and put it on the bottom of the sea at a planned depth so that life could develop, and it has sprouted an ecology that supports life, including plant life."

But is it successful as a work of art? If we are to define it as such, we have to stretch our definitions. She explains: "Ocean Landmark is an interdisciplinary work that at the time could only be described through other practices. It is known beyond an ture will be its progression as a sustaining environment for marine life and a thriving ecosystem."

Walking on the bank by Capability Brown's lake in Blenheim Park, I watch a pair of great crested grebe carrying fidgety chicks on their backs. Clearly Brown knew how to create bodies of water that were ecologically viable, although his main purpose was to delight the Duke and Duchess of Marlborough. In our era, Betty Beaumont takes this one step further, making viability the prime purpose of her art.

Beaumont's work is on show in the exhibition Anima Mundi: Soul of the World at the Herbst International Exhibition Hall, The Presidio of San Francisco, throughout October.

Martin Kemp is professor of the history of art at the University of Oxford, Oxford OX1 1PT, UK, and co-director of Wallace Kemp Artakt. His new book, Leonardo, was recently published by Oxford University Press.
30 years before. More oddly, the authors approvingly discuss the scientific contributions of Maurice Ewing and Bruce Heezen of Columbia University, both of whom opposed plate tectonics, yet make no mention of Hess, a principal architect of the theory and the man most responsible for reopening the debate in the United States.

Small errors are most relevant when they add up to a big problem, and the big problem here is the underlying theme of the book. Encapsulated by its subtitle, the suggestion is that the New Madrid quakes helped to launch the specialism of seismology, perhaps even the whole science of geology. The authors claim, for example, that geology in the early nineteenth century was "in its infancy"; that "most people who thought of themselves as scientists still believed generally in the history of the world as specified in the book of Genesis"; that many (if not most) geologists accepted the chronology of Archbishop Ussher that Earth was created on 23 October 4004 BC; and that Charles Lyell was the founder of modern geology.

These claims represent views that have long been discredited by professional historians. By 1811 there were well developed empirical and theoretical frameworks for the Earth sciences, developed primarily in continental Europe but rapidly making their mark in Britain and the United States as well. Conversely, seismology had its early roots primarily in Italy, but developed as an organized scientific discipline in the late nineteenth century in Japan, India and Germany. In Japan, the constant threat of severe earthquakes in a densely populated country hemmed in by the sea provided strong motivation; in India, Richard Dixon Oldham's study of Indian quakes led to his discovery of $\mathrm{P}$ and $\mathrm{S}$ waves; and in Germany, 
precision instrument-building led to the manufacture of good seismographs. New Madrid had little, if anything, to do with these developments. The Big One is a sloppy book, based on an erroneous premise.

Naomi Oreskes is in the Department of History, University of California, San Diego,

La Jolla, California 92093-00104, USA.

\section{Population biology on the wing}

\section{On the Wings of Checkerspots: A Model System for Population Biology}

edited by Paul R. Ehrlich \& Ilkka Hanski

Oxford University Press: 2004. 371 pp.

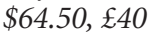

\section{Norman Myers}

Extinction is the single irreversible feature that lies at the heart of the biotic crisis overtaking the planet. But it is not the extinction of species that counts most, even though we are in the opening phase of a species extinction spasm to surpass anything since the demise of the dinosaurs and associated species 65 million years ago. More significant even than the loss of species is the extinction of populations - the discrete aggregations of individual organisms that make up species. It is populations that form the basis for the diversity and abundance of species overall. A few species comprise just one population, but most have hundreds. Worldwide there are, crudely reckoned across all species, between 1.1 billion and 6.6 billion populations. We are consigning populations to eventual extinction at a rate many times higher than that for species. This is the hidden extinction crisis, overlooked by the public and our political leaders - and it receives much less attention than it might from many biologists.

Populations also provide the ecosystem goods and services that support human economies and societies. For instance, winged insects such as butterflies and bees serve as pollinators, and disrupting this role can cause long-term cascading effects throughout ecosystems. The mass extinction of populations is propelling us into a grossly destabilized environmental future.

Because biologists can study only a very small proportion of all species and an even smaller proportion of their populations, there is a premium on identifying a few longterm field studies of populations that can shed light on key questions of evolutionary biology. Such studies have examined Galapagos finches, Gombe chimpanzees, mountain gorillas and Serengeti lions. Regrettably, there had been no such study for invertebrates until the two editors of this book, Paul

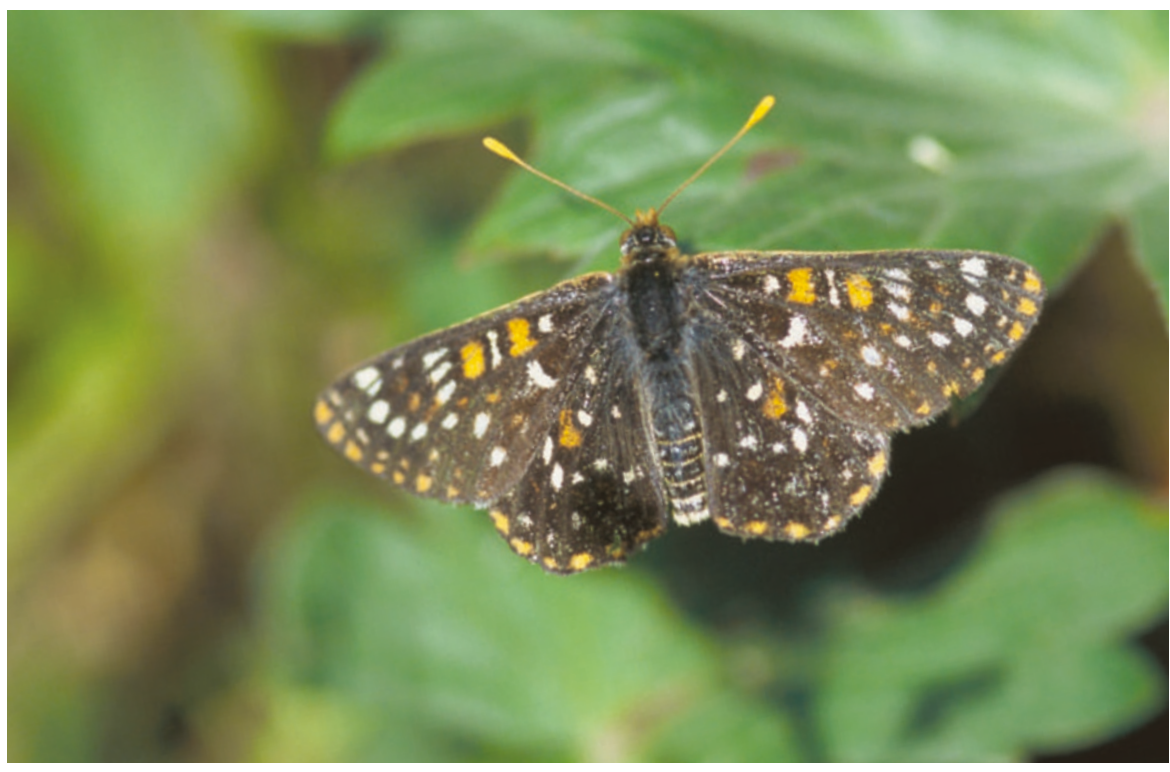

Spotting a pattern: checkerspot butterflies can help us to understand other invertebrate populations.

Ehrlich and Ilkka Hanski, started studying populations of one of the better-known categories of butterfly, the checkerspots, in central California and southern Finland.

There are at least 20,000 known butterfly species in the world, but the checkerspots make up fewer than 400 of them, and a good many of these are endangered. They are among the best-studied populations of all invertebrates, and so are crucial for our understanding of the millions of invertebrates that make up the vast majority of all species. The two editors and 13 contributing researchers have sought to use their 40-plus years of intensive field and laboratory study "to create one population biological analogue to the well-known model systems in other biological disciplines, such as the fruitflies of classical genetics". The result is a collaborative overview of model systems in population studies.

The book reviews a spectrum of the basic biology of checkerspots, including reproductive and larval biology, feeding patterns, population structure and dynamics, ecology and taxonomy. There are extended discussions of such issues as dispersal and migration, colonization, inbreeding depression, predation and parasitism, genetic differentiation, habitat fragmentation, threshold disturbances (especially by humans), climate and conservation biology. To cite the editors' ultimate purpose, the major intellectual challenge of population biology "is understanding the functioning of natural populations - how they are distributed and structured, how and why their sizes change, and how they evolve". In many respects, the book offers basic insights into the ecological and evolutionary dynamics of insect populations generally, not just of checkerspots, and thus forms a classic of modern biology.

The book provides lots of lessons for conservation biology. Many butterflies occupy successional habitats, which are in transition from one ecological state to another. So studying their populations indicates how far they can adapt their lifestyles to humandisturbed landscapes. Like many butterfly species, checkerspots favour open country. Humans have been a potent force in converting forests into open landscapes, but regrettably many of these are pesticidedoused farmlands, overgrazed pastures, golf courses and treeless subdivisions - far from suitable habitats for butterflies.

Butterflies are a staple of summer gardens, parks and other landscapes. Yet about one-fifth of European butterfly species are threatened or vulnerable, and roughly oneseventh of those in the United States and Canada are at risk in certain areas or in the whole of their ranges. The path towards extinction can be rapid. The large blue butterfly (Maculinea arion) in Britain declined from some 30 populations with an estimated 100,000 individuals in the mid-1950s to just a single population of only 250 adults in the early 1970s, and to final extinction in 1979. Conversely, several UK butterfly species have expanded their ranges in recent years, ostensibly in response to global warming.

In the main, however, the prospect for many butterflies is not propitious. This book offers many clues on how we can improve that prospect.

Norman Myers is honorary visiting fellow at Green College, Oxford University, Upper Meadow, Old Road, Oxford OX3 8SZ, UK.

\section{Correction}

In Benno Müller-Hill's review of the book on Adolf Butenandt (Nature 431, 246; 2004), it was wrongly claimed that Otmar von Verschuer told colleagues in 1946 of his and Gunter Hillman's involvement in the analysis of blood samples from Auschwitz. In fact, von Verschuer disclosed this information in a written report to the DFG in 1944. 